\title{
ENTRE A CARIDADE E A ASSISTÊNCIA: A CRIAÇÃO E O FUNCIONAMENTO DO HOSPITAL DA CARIDADE EM VIANA DO CASTELO (SÉCULOS XVIII-XIX)
}

\author{
Between charity and assistance: the creation and \\ functioning of the Hospital of Charity in Viana do \\ Castelo (18th-19th centuries)
}

Alexandra Esteves*

\begin{abstract}
RESUMO
O trabalho que nos propomos apresentar resulta da investigação que realizámos sobre o Hospital da Caridade de Viana do Castelo, cidade do norte de Portugal. Trata-se de uma instituição vocacionada para prestar assistência aos idosos que, sendo pobres, já não tinham capacidade física nem anímica para esmolar e, desse modo, angariar o seu sustento. A sua criação está estreitamente associada à iniciativa de um "brasileiro" e à sua preocupação com a condição dos entrevados.

Tendo como base a documentação existente sobre a matéria, o nosso artigo, além de referências à temática da velhice, matéria que tem merecido pouca atenção por parte da historiografia portuguesa, ocupar-se-á da fundação e dos primeiros anos do funcionamento do Hospital da Caridade, bem como dos seus beneficiários.
\end{abstract}

Palavras-chave: asilo; velhice; hospital; assistência; Viana do Castelo.

* Doutorada em História Contemporânea. Atualmente, exerce funções docentes na Faculdade de Filosofia e Ciências Sociais - Centro Regional de Braga da Universidade Católica Portuguesa e é investigadora integrada do Laboratório de Paisagens, Património e Território (LabPT), do Instituto de Ciências Sociais da Universidade do Minho. 


\begin{abstract}
The work that we propose to present results from the investigation that we carried out on the Hospital da Caridade of Viana do Castelo, city of the north of Portugal. It is an institution designed to provide assistance to the elderly who, being poor, no longer had the physical or mental ability to beg for alms and thus raise their livelihood. Its creation is closely associated with the initiative of a "Brazilian" and his concern with the condition of the inmates.

Based on existing documentation on this subject, our article, in addition to references to the subject of the elderly, a subject that has received little attention from Portuguese historiography, will focus on the foundation and the first years of the Hospital of Charity, as well as its beneficiaries.
\end{abstract}

Keywords: asylum; elderly; hospital; assistence; Viana do Castelo.

O homem do Antigo Regime encarava a morte com naturalidade e, pelo menos aparentemente, não a temia, dado o seu caráter rotineiro, e aceitava-a em nome de crenças religiosas ${ }^{1}$. Durante muito tempo, não sentiu necessidade de dividir a sua existência em etapas, em ciclos de vida, porque o inesperado era quase certo e, por isso, seria utópico definir objetivos para uma determinada faixa etária. Por conseguinte, o conceito de idoso é mais uma construção social e uma realidade cultural do que um fenómeno biológico, dado que o velho do passado não corresponde certamente ao de hoje ${ }^{2}$. No século XVIII, em Portugal, ser velho era definido como "o que está na idade que se segue à de varão. Na idade de sessenta anos, o homem he velho, o cavallo nos vinte" ${ }^{3}$. Deste modo, em setecentos, quando falamos de idosos, referimo-nos a indivíduos com 60 ou pouco mais anos.

1 Veja-se ARIÉS, Philippe. História da Morte no Ocidente desde a Idade Média. Lisboa: Teorema, 1988

2 Sobrado CORREA, Hortensio, "Vellos e "mozos vellos". El papel socioeconómico y cultural de la vejez en la Galicia de la Edad Moderna". SEMATA, Ciencias Sociais e Humanidades, 2006, vol. 18, p. 274.

3 BLUTEAU, Rafael. Diccionario da lingua portugueza composto pelo padre D. Rafael Bluteau, reformado, e accrescentado por Antonio de Moraes Silva natural do Rio de Janeiro. Lisboa: Na Officina de Simão Thaddeo Ferreira, p. 387. 
O passado histórico é, assim, determinante na variabilidade da conceção da velhice, na forma como esta vai sofrendo mutações ao longo dos tempos, determinadas por condicionantes económicas, sociais e políticas. Homens e mulheres não entravam na velhice em simultâneo nem apenas em resultado da idade, mas antes em função de outros fatores: uma mulher velha era uma mulher que se esgotava na procriação; o homem era considerado velho quando já não tinha forças para pegar em armas ou quando estava incapaz de trabalhar a terra ou na oficina.

Apesar do elevado número de fontes ao dispor, que vão desde tratados médicos, passando por documentos legislativos até aos textos literários, pouco se tem escrito sobre os idosos e, em particular, sobre as condições em que viviam o ocaso da vida ${ }^{4}$. Para esse esquecimento concorre o facto de, até à época da industrialização e do crescimento urbano, prevalecer o que muitos designam de "velhice invisível", que nalgumas sociedades se manteve até ao século $\mathrm{XX}^{5}$. Era uma velhice ancorada em estratégias familiares, que homens e mulheres procuravam acautelar na fase adulta, com base num património passível de transmissão mediante o cumprimento de certas condições.

Neste trabalho, não cabe a análise das transformações que, a partir do século XIX, se verificaram nesse relacionamento, na sequência da revolução industrial e da deslocação das populações para o espaço urbano, que acabaram por comprometer a continuidade da família alargada e do elemento patrimonial como garante do amparo na velhice. Aliás, essas mudanças ditarão o reconhecimento de uma nova etapa da vida - a terceira idade -, na qual, pela perda da força anímica e física, o indivíduo, enquanto ser produtivo, deixa de ser considerado útil ${ }^{6}$. No sentido de proteger os idosos, em particular

4 Confira-se THANE, Pat. La vejez en la historia inglesa. SEMATA, Ciencias Sociais e Humanidades, 2006, vol. 18, p. 13.

5 Isidro Dubert fala de uma velhice visível e reconhecida na Galiza do século XVIII, fruto do quadro demográfico existente. Também salienta a existência de um contexto marcado por desigualdades sociais e até de género, destacando a situação das mulheres idosas. DUBERT, Isidro. Vejez, familia y reproducción social en la España de los siglos XVIII-XIX. Revista de Demografía Histórica, 2, 2008, pp. 87-122

6 Sobre este assunto leia-se P. Gutton. Naissance du vieillard: essai sur l'histoire des rapports entre vieillards et la sociètè en France, París, 1988. SOBRADO CORREA, Hortensio. Vellos e "mozos vellos". El papel socioeconómico y cultural de la vejez en la Galicia de la Edad Moderna. SEMATA, Ciencias Sociais e Humanidades, 2006, vol. 18: 271-306. 
os desprovidos dos apoios familiares e informais de outrora e, consequentemente, caídos numa situação de abandono, muitos países europeus lançaram medidas sociais e respostas assistencialistas, materializadas, no século XIX, na fundação de asilos para os desvalidos ${ }^{7}$.

A noção de desamparo parece quase adstrita ao século XIX, como resultado das transformações que nele tiveram lugar. No entanto, ela também se inscreve no Antigo Regime, agravada pela ausência de medidas de proteção social por parte do Estado. Por outro lado, esta tendência para a demarcação de diferentes etapas que marcam a vida humana é uma construção moderna. Tal como não se reconhecia, até ao século XVIII, a noção de infância, também não se considerava a existência de uma "terceira idade", o que conduz a limitações na existência de fontes sobre esta fase da vida ${ }^{8}$.

Dada a escassez de estudos sobre a velhice em Portugal e a ausência de conclusões sustentadas por trabalhos de natureza histórica, somos levadas a abdicar da pretensão de traçar um retrato mais completo e objetivo sobre a assistência prestada nesta fase da vida ${ }^{9}$. Todavia, os trabalhos sobre as misericórdias, para o período moderno e contemporâneo, mostram o importante papel que estas instituições têm desempenhado na assistência aos idosos, não apenas no plano material, mas também espiritual ${ }^{10}$. Nesta ajuda inclui-se a

7 Leia-se FERNÁNDEZ, Fernández, Carlos M.; SÁNCHEZ GARCIA, Jesús Ángel. Espacios para el refugio. La asistencia a la vejez y los asilos en Galicia. SEMATA, Ciencias Sociais e Humanidades, 2006, vol. 18, p. 169.

8 Sobre este assunto leia-se MINOIS, Georges. História da velhice no ocidente: da antiguidade ao renascimento. Lisboa: Teorema, 1999.

9 A nível europeu, a temática começou a ser tratada no âmbito da demografia histórica, da história das mentalidades e da história da família, nos anos 80 do século XX. Sobre este assunto veja-se FERNÁNDEZ CORTIZO, Camilo. Mujer, vejez y grupo doméstico en la Galicia rural meridional a finales del Antiguo RégimeN. Nuevo Mundo. Mundos Nuevos [Online], consultado o 12 Fevereiro 2016. URL: http://nuevomundo.revues.org/29553; DOI: 10.4000/nuevomundo.29553. Em Espanha, os trabalhos sobre esta temática são em grande número. Consulte-se ainda BOURDELAIS, Patrice; GOURDON, Patrice; VIRET, Jérôme-Luther. La vejez en Francia, siglos XVII-XX. Entre las regulaciones familiares, las representaciones sociales y los intereses científicopolíticos. SEMATA, Ciencias Sociais e Humanidades, vol. 18, p. 32.

10 Segundo Maria Marta Lobo de Araújo, a Misericórdia de Vila Viçosa prestava auxílio aos mais idosos desde o século XVII. Confira-se ARAÚJO, Maria Marta Lobo de. A protecção aos velhos na Misericórdia de Vila Viçosa (século XIX). In SANTOS, Carlota (coord.). Família, Espaço e Património. Porto: CITCEM - Centro de Investigação Transdisciplinar «Cultura, Espaço e Memória», 2011, pp. 201-222. 
gestão de asilos para entrevados, como sucedia na Santa Casa da cidade do Porto, e na presença em róis de pobres ${ }^{11}$.

Num tempo em que a intervenção do Estado na área assistencial era diminuta, as ações individuais, ditadas pela prática da caridade, assumiam particular relevância. $\mathrm{O}$ catolicismo considerava as boas ações um elemento abonatório a favor da salvação da alma e da abreviação das provações do Purgatório. Por isso, homens e mulheres, dentro das suas possibilidades, tornavam-se benfeitores e deixavam donativos a instituições que se dedicavam a obras assistenciais, nomeadamente a misericórdias e hospitais, que, deste modo, contavam com uma importante fonte de financiamento para a sua atividade benemerente.

$\mathrm{O}$ maior risco de enfermidades, o abandono a que estavam sujeitos, a debilidade física e anímica para trabalhar, entre outros fatores, colocavam os idosos entre os grupos mais suscetíveis de cair na miséria. Todavia, como se pode constatar no gráfico 1 , não constituíam o grosso da população indigente do distrito de Viana do Castelo, pelo menos nos anos de 1856, 1858, 1859 e 1862, para os quais existem dados e que podemos analisar.

11 Confira-se LOPES, Maria Antónia. Pobreza, assistência e controlo social. Coimbra 1750-1850, vol. II. Viseu: Palimage Editores, 2000, pp. 67-76. 


\section{Gráfico 1 - Idade dos mendigos existentes no distrito de Viana do Castelo}

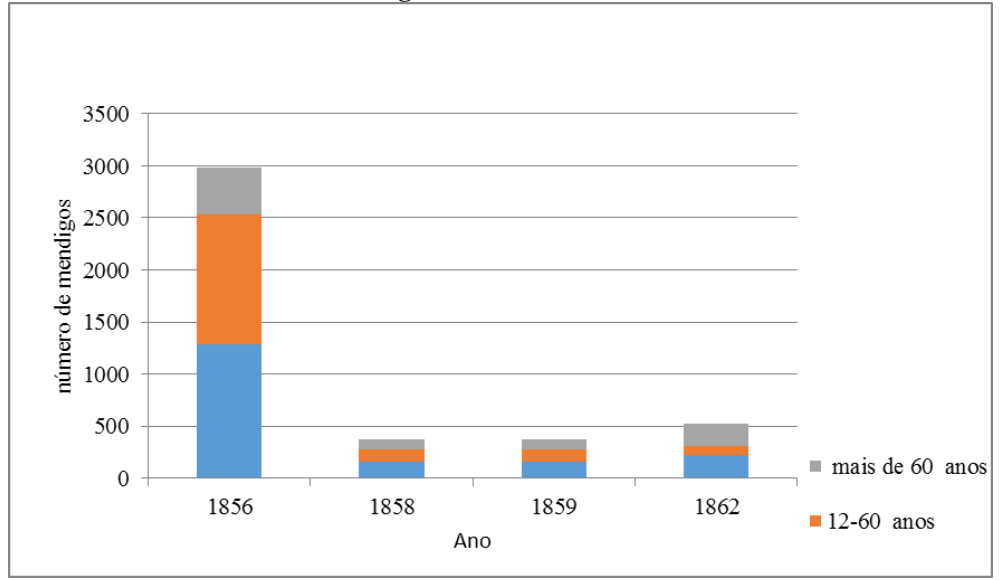

Fonte: AHGCVC, Assistência Social e Saúde Pública, Correspondência recebida relativa a mendigos e vadios, mapas estatísticos dos mendigos existentes nos vários concelhos, n. ${ }^{\circ}$ 1.16.6.9-6, não paginado. Relatórios sobre o Estado da Administração Pública nos districtos administrativos do Continente do Reino e Ilhas Adjacentes em 1856, Lisboa, Imprensa Nacional, 1857; Relatórios sobre o Estado da Administração Pública nos districtos administrativos do continente do reino e ilhas adjacentes em 1857, Lisboa, Imprensa Nacional, 1858; Relatórios sobre o Estado da Administração Pública nos districtos administrativos do Continente do Reino e Ilhas Adjacentes em 1860, Lisboa, Imprensa Nacional, 1865.

Foi por um ato de altruísmo que José da Costa Pimenta Jarro, natural da freguesia de Cabaços, do concelho de Ponte de Lima, idealizou e fundou, em janeiro de 1780, a Congregação de Nossa Senhora da Caridade, tendo contado para o efeito com a colaboração de algumas das mais ilustres figuras da sociedade vianense ${ }^{12}$. O objetivo principal era recolher donativos para o sustento de velhos e entrevados, sem meios para garantir o seu sustento, de Viana da Foz do Lima ${ }^{13}$. Pimenta Jarro era um "brasileiro de torna-viagem", que tinha conseguido granjear fortuna no Brasil como oficial de ourives.

12 Arquivo da Congregação e Hospital dos Velhos Entrevados da Nossa Senhora da Caridade (doravante ACHVENSC), Livro de termos de Admissão de irmãos desde a função em 1780 , fl. 4-6v.

13 ABREU, Alberto Antunes. José da Costa Pimenta Jarro. In d'ABREU, João Gomes (coord.). Figuras Limianas. Ponte de Lima: Câmara Municipal de Ponte de Lima, 2008, p. 136. 
À semelhança de outros emigrantes que regressaram ao torrão natal, investiu parte do dinheiro amealhado numa obra filantrópica. Aliás, esta prática assumirá contornos mais evidentes no século seguinte, na região do Alto Minho. Vários equipamentos destinados a doentes, crianças e idosos foram então criados com legados de "brasileiros" 14 . Muitos beneméritos procuravam, por essa via, o reconhecimento social ou até a concretização de ambições políticas. Todavia, não parece ter sido esse o caso de Pimenta Jarro, dado que, após o regresso definitivo do Brasil, recolheu-se no convento franciscano da Arrábida.

No século XVIII, verifica-se a proliferação de agremiações que incluem a "caridade" na sua designação, embora com práticas e destinatários diversos. Se umas estavam vocacionadas para auxiliar os doentes ou os idosos, outras estavam mais voltadas para o apoio aos presos ou para o combate à ociosidade. Aliás, não havia sequer uniformização na nomenclatura, inclusive na cidade de Lisboa, como refere Laurinda Abreu ${ }^{15}$.

São também muitas as questões que se colocam sobre estas congregações de inspiração religiosa e para as quais não encontramos respostas. No caso da Congregação de Nossa Senhora da Caridade, não conseguimos apurar o papel da Igreja na sua criação. Reconhecese, no entanto, o seu apoio, a presença e inspiração. Faltam, portanto, os estudos e a informação sobre a localização dessas instituiç̃os que marcaram a sociedade setecentista em diversas localidades. É de assinalar o seu aparecimento em terras onde já existiam misericórdias, às quais, de certo modo, faziam concorrência ${ }^{16}$. Todavia, aquando da

14 Aquando da construção de estruturas assistenciais, mandava-se a notícia aos emigrantes da terra para que também eles contribuíssem para a sua concretização. Consulte-se ARAÚJO, Maria Marta Lobo de. A presença dos brasileiros no santuário de Nossa Senhora de Porto de Ave (séculos XVIII a XX). In PEREIRA, Conceição Meireles; SOUSA, Fernando de; MARTINS, Ismênia de Lima. A Emigração Portuguesa para o Brasil. Parte II. Porto: Centro de Estudos da População, Economia e Sociedade, Edições Afrontamento, 2007, p. 189. Sobre as causas da emigração rumo ao Brasil consulte-se RUSSELL-WOOD, A. J. R. A emigração: fluxos e destinos. In BETHENCOURT, Francisco; CHAUDHURI, Kirti (dir.). História da Expansão Portuguesa. vol. 3. Lisboa: Círculo de Leitores, 1997, pp. 158-168.

15 ABREU, Laurinda. Pina Manique. Um reformador no Portugal das Luzes. Lisboa: Gradiva, 2013, pp. 48-58.

16 Sobre os fatores distintivos para a hierarquização das confrarias, veja-se PENTEADO, Pedro. Confrarias. In AZEVEDO, Carlos Moreira (Dir.). Dicionário de História Religiosa, Lisboa: Círculo de Leitores, 2000, p. 459-470. 
fundação da Congregação da Caridade de Viana da Foz do Lima, não se descortinam quaisquer sinais de rivalidade, até porque o seu primeiro momento celebrativo teve lugar na igreja da Santa Casa, nem se verifica qualquer situação de crise ou de conflito com a Igreja ou com a Coroa ${ }^{17}$. Todavia, no compromisso da Confraria da Caridade do Senhor Jesus dos Desamparados e Senhora das Dores, da vila de Oeiras, por exemplo, é possível encontrar, entre os argumentos que justificam a criação desta irmandade, a inexistência de uma instituição que pudesse acudir aos mais necessitados ${ }^{18}$.

A atividade assistencial da Congregação da Caridade não se limitou à distribuição de esmolas pelos mais pobres, dado que também havia a pretensão de conseguir um espaço destinado ao seu acolhimento. Com esse objetivo, Pimenta Jarro adquiriu uma casa com quintal, situada junto ao Campo de Santo António, que doou à Congregação, para que nela fosse instalado um hospital, onde pudessem ser recolhidos os idosos entrevados e desamparados. Todavia, a concretização desse propósito aconteceu apenas em 1784, depois de efetuados alguns melhoramentos. Posteriormente, foram adquiridos outros espaços contíguos para responder à crescente procura de apoio.

Desconhecemos muitos dos acontecimentos mais marcantes da vida de Pimenta Jarro, sendo muitas as perguntas sem resposta. O que o levou a investir nesta obra? Por que razão optou por Viana da Foz do Lima, sendo natural de Ponte de Lima? Conjetura-se que o facto de não ter família neste concelho terá pesado na sua opção ${ }^{19}$. Por que motivo, já no fim da sua vida, se recolheu no convento de Franciscanos Observantes da Arrábida?

A saída de cena de Pimenta Jarro não significou o fim do seu projeto assistencial. Bernardo de Araújo de Barros, natural de Viana

17 Sobre a Misericórdia de Viana da Foz do Lima, no período compreendido entre os séculos XVI e XVIII, veja-se MAGALHÃES, António. Práticas de Caridade na Misericórdia de Viana da Foz do Lima (séculos XVI-XVIII). Viana do Castelo: Santa Casa da Misericórdia de Viana do Castelo, 2012.

18 Compromisso ou regras para o bom governo da nova confraria da charidade que debaixo da invocação do Senhor Jesus dos Dezamparados e Senhora das Dorews se estabeleceu nest Paroquial Igreja de Nossa Nossa Senhor da Purificação da Viçç 'Oeyras, Oeiras, (s.n.), 1806, fl. IV.

19 ABREU, Alberto A. A Congregação de Nossa Senhora da Caridade. Viana do Castelo: Nossa Senhora da Caridade, 2005, p. 29. 
da Foz do Lima, procurou solidificar e dar seguimento à obra do instituidor. Os estatutos da Congregação datam de 17 de novembro de 1790, sendo aprovados por alvará régio e confirmados pela autoridade eclesiástica em 1805. Segundo o disposto nesse documento, o Hospital devia acolher homens e mulheres que nada tinham de seu e que, devido à idade avançada ou à incapacidade resultante da velhice ou dalguma limitação física, já não podiam esmolar ${ }^{20}$. Por conseguinte, esta instituição não se destinava a pedintes, uma vez que nela apenas podia ingressar quem não estava em condições de mendigar. Mais uma vez, convoca-se aqui a comparação com a confraria congénere de Oeiras, para demonstrar a inexistência de um padrão. Esta irmandade socorria os pobres que mendigavam, e não apenas os entrevados, e estava vocacionada para assistir os doentes da paróquia onde foi construída. Caso a gravidade da enfermidade o justificasse, comprometia-se a transportar os pacientes para o hospital de São José, em Lisboa ${ }^{21}$. Obrigava-se ainda a acompanhar os pobres e doentes da paróquia no seu funeral e a fornecer o seu esquife para o efeito. No caso da instituição de Viana da Foz do Lima, esses acompanhamentos eram reservados aos irmãos e aos inválidos que se encontravam no seu Hospital ${ }^{22}$.

O entrevado não deve ser entendido apenas como o velho. De acordo o vocabulário da época, "entrevar" significa "ficar tolhido; e baldado dos membros, és e braços" "23. Assim, será limitativo considerar que o Hospital da Caridade era destinado apenas a idosos. $\mathrm{Na}$ realidade, a sua ação abrangia um público mais vasto, que, com entrada no século XIX, se diversificará ainda mais com a presença de

20 Sobre o aparecimento de asilos para velhos na vizinha província espanhola da Galiza leia-se FERNÁNDEZ, Fernández, Carlos M.; SÁNCHEZ GARCÍA, Jesús Ángel. Espacios para el refugio. La asistencia a la vejez y los asilos en Galicia”... op. cit, p. 103.

21 Compromisso ou regras para o bom governo da nova confraria da charidade que debaixo da invocação do Senhor Jesus dos Dezamparados e Senhora das Dorews se estabeleceu nest Paroquial Igreja de Nossa Nossa Senhor da Purificação da Viçç 'Oeyras, Oeiras, (s.n.), 1806, fl. 1v.

22 Sobre os acompanhamentos na morte leia-se FERRAZ, Tiago. Acompanhar ao outro mundo: A morte nas confrarias de Braga no século XVIIII. Estudo Preliminar. CEM. Cultura, Espaço e Memória, 3, 2012, pp. 163-177.

23 Bluteau, Rafael, Diccionario da lingua portugueza composto pelo padre D. Rafael Bluteau, reformado, e accrescentado por Antonio de Moraes Silva natural do Rio de Janeiro..., op. cit, p. 515 . 
cegos, como se pode observar no gráfico 1. A inexistência de estabelecimentos para acolher invisuais, surdos e mudos, fez com que, nesse século, estes fossem acolhidos em instituições destinadas a idosos, entrevados ou até a leprosos, como sucedia no hospital para lázaros, na cidade do Porto, que também passou a acolher surdos e mudos.

Decorridos catorze anos sobre a admissão dos primeiros entrevados, que aconteceu em 1784, o Hospital da Caridade albergava apenas oito idosos, até porque não tinha capacidade para mais. Em 1825, a instituição adquiriu outra casa e o quintal contíguo. À medida que se avança na centúria de oitocentos, a população idosa, cega e entrevada, tende a aumentar, conforme se pode constatar no gráfico 1.

À medida que cresce a procura, o Hospital vai respondendo com a ampliação das instalações. Mesmo assim, em meados da centúria oitocentista, era considerado de pequena dimensão. Salientese, no entanto, que, com exceção de Viana do Castelo ${ }^{24}$ e de Ponte de Lima, as restantes localidades do distrito dispunham de pequenas estruturas hospitalares ou nem sequer tinham hospital geral ${ }^{25}$.

A irmandade da Caridade era gerida por uma Mesa, eleita anualmente. A votação tinha lugar no dia 26 de abril de cada ano ${ }^{26}$. Este órgão tinha como figura maior o superior. Era o detentor da chave do cofre e competia-lhe presidir a todas as Mesas, superintender os ingressos e cuidar do sufrágio da alma dos falecidos, zelar pelo funcionamento do Hospital, que devia visitar com regularidade, se possível de dois em dois meses. Seguia-se, na linha hierárquica, o vice superior, que substituía o superior na sua ausência ou impedimento. Por conseguinte, devia reunir as qualidades que eram exigidas a este. $\mathrm{O}$ andador tinha a missão de participar o falecimento de algum irmão ou entrevado, bem como de informar os

24 Em 1848, a rainha D. Maria II elevou Viana da Foz do Lima à categoria de cidade, passando então a designar-se Viana do Castelo.

25 Sobre este assunto veja-se ESTEVES, Alexandra. Comer, sarar e descansar: o quotidiano do hospital de Monção no século XIX. (no prelo). A existência de hospitais de reduzidas dimensões verificava-se noutras zonas de Portugal. Segundo Maria Antónia Lopes, o hospital de Bragança, em 1823, acolhia entre quatro e cinco doentes. Confirme-se LOPES, Maria Antónia, PAIVA, José Pedro (dir. científica). Portugaliae Monumenta Misericordiarum. Sob o signo da mudança: do reinado de D. José a 1834, volume 7, Lisboa, União das Misericórdias, 2007, p. 27.

26 ACHVENSC, Estatutos para a boa orientação da caridade a favor dos entrevados, pobres, destituídos de meyos para se poderem alimentar, fls. 3-4. 
membros da Mesa e da Junta das respetivas reuniões, deslocando-se às suas casas, munido de campainha ${ }^{27}$. Na categoria abaixo, constavam os definidores, que deviam ser dois, exigindo-se aos pretendentes a este cargo que tivessem desempenhado outras funções na Congregação. Entre outras obrigações, deviam acompanhar os atos processionais organizados pela instituição. Para o exercício do cargo de secretário, também estavam previstos alguns requisitos. Como não poderia deixar de ser, tinha que saber ler, escrever e contar. Competia-lhe guardar todos os livros da Irmandade e registar as entradas e os óbitos dos irmãos. A função de tesoureiro teria de ser desempenhada por uma pessoa com a reputação de confiável, dado que também teria uma chave do cofre e seria responsável pelas alfaias e pelo recebimento das esmolas de entrada dadas pelos irmãos. Não podia efetuar qualquer despesa sem consentimento do superior ${ }^{28}$. No caso do falecimento de qualquer membro, o tesoureiro devia avisar o andador desta ocorrência, para que este, por sua vez, informasse os restantes membros. Os procuradores tinham uma missão muito específica: conseguir esmolas para os entrevados pobres. Para isso, deviam assumir o compromisso de fazer um peditório no primeiro domingo de cada mês e nos dias santos ${ }^{29}$. Teria lugar durante a noite e os participantes cantavam ave-marias, recitavam algumas passagens das Sagradas Escrituras e iam munidos de campainhas para avisar as pessoas da sua passagem ${ }^{30}$.

Nas ocasiões de celebração pública, os irmãos da Congregação da Caridade deviam exibir a insígnia que lhes tinha sido entregue. Tinham diversas obrigações. Uma delas consistia no pagamento de um anual, no valor de três vinténs, que teria de ser liquidado no mês antes da eleição. De certo modo, este encargo funcionava como um mecanismo de seleção dos candidatos ao ingresso na irmandade. No rol dos deveres, instituídos com base em

27 ACHVENSC, Estatutos para a boa orientação da caridade a favor dos entrevados, pobres, destituídos de meyos para se poderem alimentar, fls. 6v.-7.

28 ACHVENSC, Estatutos para a boa orientação da caridade a favor dos entrevados, pobres, destituídos de meyos para se poderem alimentar, fls. 6-6v.

29 ACHVENSC, Estatutos para a boa orientação da caridade a favor dos entrevados, pobres, destituídos de meyos para se poderem alimentar, fls. $7 \mathrm{v}-8$.

30 ACHVENSC, Estatutos para a boa orientação da caridade a favor dos entrevados, pobres, destituídos de meyos para se poderem alimentar, fl. $8 \mathrm{v}$. 
preocupações salvíficas, constavam o acompanhamento dos irmãos defuntos e os sufrágios pela sua alma.

O homem moderno tinha consciência da transitoriedade da vida e da imortalidade da alma. Apesar do carácter secundário do corpo, o momento de despedida devia ser acompanhado. Aliás, a morte, neste período, era perspetivada deste modo: assistida por familiares, amigos e confrades, e pública, sentida pela comunidade ${ }^{31}$. Assim se entende o ingresso nas associações confraternais. $\mathrm{O}$ poder económico e o reconhecimento social manifestavam-se na capacidade de participação em confrarias e o momento fúnebre devia materializar os valores e as práticas que norteavam o ingresso de homens e mulheres nessas irmandades. Daí a organização dos cerimoniais aquando da morte dos irmãos, promovidos pela Congregação da Caridade: o andador, munido de uma campainha, anunciava o seu falecimento pelas ruas; os confrades acompanhavam o corpo até à sepultura; duas tochas iluminavam o momento de passagem do defunto; por cada irmão defunto eram rezadas cinco missas ${ }^{32}$.

Os irmãos tinham várias prerrogativas, como, por exemplo, indulgências e, se fossem pobres, entrada facilitada no Hospital da Caridade $^{33}$. Em 1791, com o propósito de alargar os serviços prestados aos entrevados e velhos, foi decidido que a instituição recebesse irmãos das freguesias de Viana Foz do Lima, mais precisamente dois por cada uma, com a obrigação de organizarem um peditório de trigo e milho, por altura de São Miguel, ou seja, na época das $\operatorname{colheitas}^{34}$. O objetivo era aumentar os rendimentos da Congregação e, desse modo, melhorar a assistência hospitalar.

As instalações eram geridas por um hospitaleiro. Competialhe zelar pela sua limpeza e asseio, bem como pela roupa de cama e de vestir dos entrevados. Devia tratar os utentes com afeto e dedicação e participar a sua morte. No período em análise, ou seja, entre 1790 e 1834, o cargo foi sempre desempenhado por elementos

31 A morte solitária, durante este período, era temida. Perrot, Michelle, História dos Quartos, Lisboa, Teodolito, 2012.

32 ACHVENSC, Estatutos para a boa orientação da caridade a favor dos entrevados, pobres, destituídos de meyos para se poderem alimentar, p. 6.

33 ACHVENSC, Estatutos para a boa orientação da caridade a favor dos entrevados, pobres, destituídos de meyos para se poderem alimentar. p. 15.

34 ACHVENSC, Livro de Actas 1, fl. $11 \mathrm{v}$. 
do sexo feminino, que também desempenhavam funções na área da enfermagem. Todavia, em 1829, surgiu a figura da regente, também mulher, que era coadjuvada pelos criados nas tarefas de limpeza e na assistência aos doentes.

Sendo lugar de manifestação de poderes e de existência de hierarquias, na Congregação da Caridade também ocorriam conflitos e querelas. Em caso de incumprimento das obrigações estatuídas, os irmãos eram avisados e podiam, inclusive, ser riscados ${ }^{35}$. Se tal se justificasse, a instituição não se inibia de tomar esta decisão radical, apesar das dificuldades financeiras por que passava. Os seus rendimentos dependiam dos anuais dos irmãos, dos valores angariados nos peditórios, dos legados em dinheiro, das propriedades que lhe eram doadas em testamento e dos poucos haveres que os internados deixavam.

No período compreendido entre 1786 e 1880, verifica-se um equilíbrio entre as entradas e os falecimentos de homens e mulheres no Hospital da Caridade. A exceção encontra-se nos anos de 1787, quando ingressaram dezasseis entrevados e morreram onze, e em 1791, quando o número de falecimentos superou o dos ingressos, tendo entrado nove e morrido treze entrevados. Dada a idade avançada dos seus utentes, não é de estranhar a presença assídua do espectro da morte na instituição. 
Gráfico 2: Entradas e falecimentos no Hospital da Caridade (1786-1880)

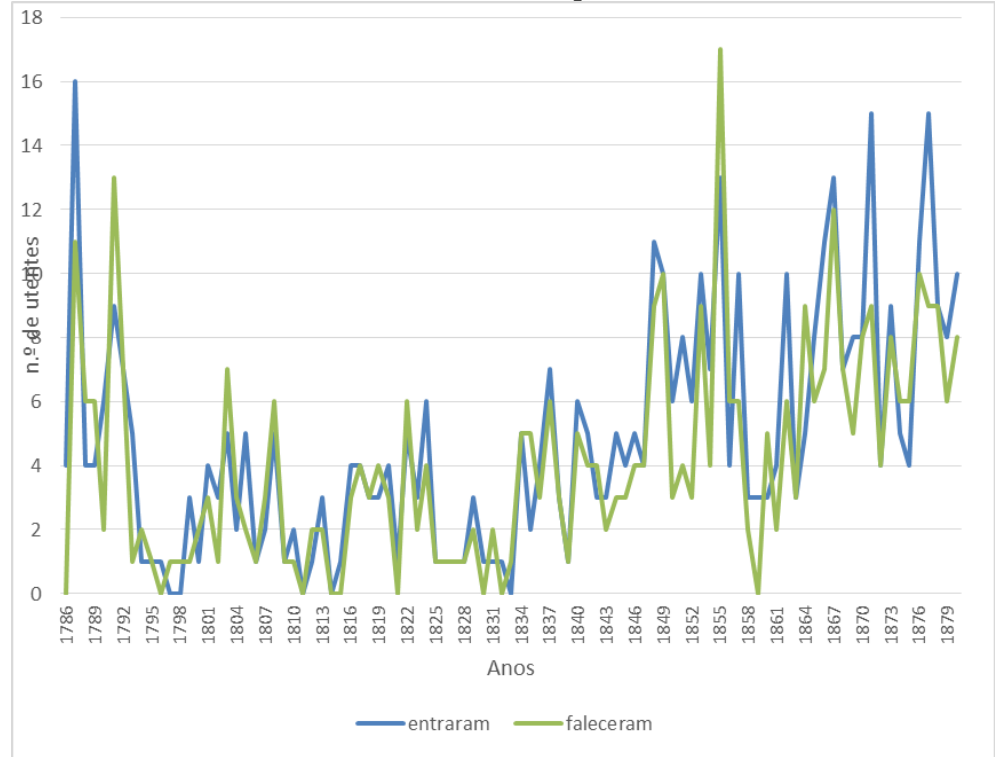

Fonte: ACHVENSC, Livros de admissão de irmãos

No século XIX, as instalações continuavam a ser insuficientes para responder à procura. Dispunha apenas de um salão térreo, onde se alinhavam as alcovas dos utentes. Destes conhecemos o número e o sexo, dado que o Hospital acolhia homens e mulheres, e, como podemos verificar no gráfico 3 , registou-se um aumento do número de doentes ao longo daquele século. 
Gráfico 3: Número de homens e mulheres que ingressaram no Hospital da Caridade (1786-1880)

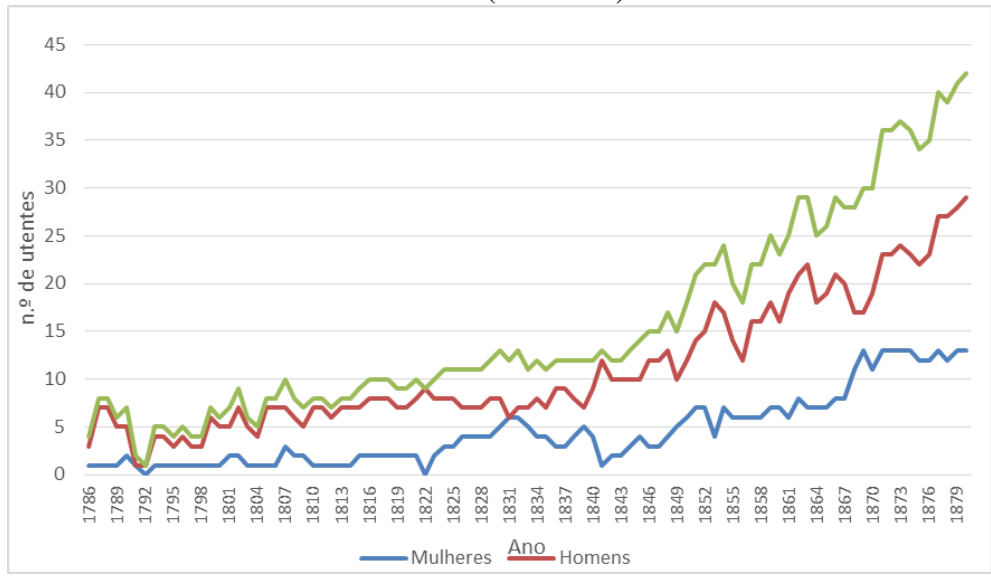

Fonte: ACHVENSC, Livros de admissão de irmãos.

À medida que se caminha para a centúria oitocentista, tende a crescer o número de utentes, sendo que o número de mulheres foi sempre superior ao de homens, exceto no ano de 1831, no qual se verificou um número idêntico de homens e mulheres. Refira-se que, em ocasiões de instabilidade, como as que resultaram das invasões francesas ou da guerra civil de 1832-1834, aumentou o ingresso de entrevados, como se pode observar no gráfico 3.

O aumento da população asilada acontece sobretudo a partir de 1850. No ano anterior, tinha assumido a direção da instituição, cargo que exerceu durante vários anos, um homem que marcou a sua missão: Mateus José Barbosa Silva. Não só conseguiu a necessária estabilidade financeira, como levou a cabo importantes obras na estrutura existente para albergar os asilados. Até então, desde o tempo de Pimenta Jarro, estavam enfiados em cubículos, apesar da realização dalgumas intervenções. A tendência de subida do número de beneficiários manteve-se nos anos subsequentes.

Outra evidência, possível de constatar através da análise do gráfico 3, tem a ver com a predominância de utentes do sexo feminino no Hospital da Caridade. Como já referimos, em Portugal não abundam os estudos sobre instituições vocacionadas para idosos, mas 
os trabalhos publicados, quer em território nacional, quer alémfronteiras, evidenciam o caráter eminentemente feminino deste tipo de assistência. São vários os fatores que concorrem para esta realidade, em particular na região do Alto Minho. Em resultado da emigração, que levava muitos homens a procurar melhorar a sua sorte noutras paragens, a população feminina superava a masculina, que se traduzia em elevadas taxas de feminilidade e no elevado número de mulheres sós, que, no seu quotidiano, se viam confrontadas com dificuldades de toda a ordem ${ }^{36}$.

Nos séculos XVIII e XIX, a solidão feminina, sobretudo em idades avançadas, quando falta já força física e anímica para garantir a subsistência, significava, geralmente, o caminho para a pobreza. Daí a importância que o casamento tinha para a mulher deste período e a preocupação que existia de facilitar o matrimónio de raparigas órfãs e pobres, que tinham mais dificuldades em aceder ao mercado matrimonial, através da concessão de dotes por particulares, misericórdias e confrarias. A sociedade de então considerava que uma rapariga solteira estava mais sujeita a cair na desonra e na indigência ${ }^{37}$. A situação das mulheres viúvas também podia ser bem difícil, pois ficavam com uma casa para sustentar, um património para cuidar e filhos para educar. Muitas, incapazes de suportar esses encargos, não tinham outra alternativa que não fosse recorrer à caridade.

36 No estudo que realizou para o Alto Minho, Henrique Rodrigues verificou que, entre 1835 e 1860, 96\% dos indivíduos que emigraram eram do sexo masculino. Esta emigração intensificava-se nos períodos de maior instabilidade política e económica, sobretudo com as crises que se fizeram sentir no setor agrícola, de que são exemplo a do oídio, a partir de 1852, a do azeite e a cerealífera, que levavam muita gente a partir em busca de melhores condições de vida. RODRIGUES, Henrique. Emigração e Alfabetização. O Alto Minho e a Miragem do Brasil. Viana do Castelo: Governo Civil de Viana do Castelo, 1995, pp. 47-58.

37 Sobre a participação das misericórdias na dotação de raparigas órfãs leia-se Veja-se ARAÚJO, Maria Marta Lobo de. Casadas com trigo e cevada. Os dotes das órfãs da Misericórdia de Portel no século XVIII. Faces de Eva: Estudos sobre a mulher, 20, 2008, p. 63. Veja-se igualmente RIBEIRO, António Magalhães da Silva. Práticas de caridade na Misericórdia de Viana da Foz do Lima (séculos XVI-XVIII). Braga: Universidade do Minho, 2009, p. 907. Tese de doutoramento policopiada. Confirme-se ARAÚJO, Maria Marta Lobo de. Dotar para casar: dotes e órfãs do padre Francisco Correia da Cunha 1750-1890. Ler História, 44, 2003, pp. 62-63. Sobre os dotes instituídos para casar parentes leia-se ARAÚJO, Maria Marta Lobo de. Retalhos de vidas: a assistência às mulheres pobres na Misericórdia de Ponte de Lima (sécs. XVII e XVIII). Mínia, 8-9, 2000-2001, pp. 170-172. 
Importa referir a ausência de estudos sobre as respostas sociais destinadas a idosos e a entrevados desamparados do Alto Minho, que, noutras regiões da Europa, eram assistidos por grémios e confrarias. Todavia, reconhecemos que, se esta solução escasseava no século XVIII, pelo menos em termos institucionais, já na centúria seguinte houve melhorias nesse domínio, graças a iniciativas particulares, em particular à filantropia de "brasileiros", como José da Costa Pimenta Jarro, que deixaram importantes legados para a criação de instituições sociais, muitas delas destinadas a idosos ${ }^{38}$.

Em 1804, consciente do aumento da procura, a Mesa da Congregação resolveu adquirir as casas contíguas ao Hospital, com o objetivo de proceder à sua ampliação ${ }^{39}$. Já em 1826 , foi decidido alargar as enfermarias, obra que seria financiada com as esmolas obtidas através dos peditórios gerais ${ }^{40}$.

Nos finais do século XVIII, os princípios higienistas começam a impor-se na Europa, como forma de evitar a propagação de doenças, e a água volta a ser considerada um elemento essencial na divulgação e inculcação dos hábitos de higiene ${ }^{41}$. Estudos recentes realizados em Portugal mostram que, na Idade Moderna, havia preocupação com a limpeza dos espaços hospitalares e com a higiene dos enfermos ${ }^{42}$. Todavia, tratava-se de tarefas de difícil execução, devido à falta de meios e, muitas vezes, à resistência dos próprios utentes $^{43}$. Um dos problemas do Hospital da Congregação da Caridade tinha a ver com a inexistência de um sistema de

38 Caso de José Manuel Taveira no concelho vizinho de Ponte de Lima. ESTEVES, Alexandra. A intervenção dos "brasileiros" nas instituições de assistência à saúde no norte de Portugal (século XIX). In ARAÚJO, Maria Marta Lobo de; ESTEVES, Alexandra; COELHO, José Abílio; FRANCO, Renato (Coords.). Os Brasileiros enquanto agentes de mudança: poder $e$ assistência. Braga: CITCEM, Fundação Getúlio Vargas, 2013.

39 ACHVENSC. Livro de Actas 1, fl. 23.

40 ACHVENSC. Livro de Actas 1, fl. 5v.

41 Confirme-se WEAR, Andrew. The History of Personal Hygiene. In BYNUM, W.F.; PORTER, Roy (Eds.). Companion Encyclopedia of the History of Medicine. vol. 2. London and New York: Routledge, 2001, pp. 1300-1301.

42 ARAÚJO, Maria Marta Lobo de. Memórias e quotidiano: as visitas e as devassas ao hospital de S. Marcos de Braga na Idade Moderna. Braga: Santa Casa da Misericórdia de Braga, 2014. Sobre a associação da falta de água e higiene à doença leia-se VIGARELLO, George. $O$ limpo e o sujo. A higiene do corpo desde a Idade Média. Lisboa: Fragmentos, 1988, pp. 141-143.

43 Sobre a falta de higiene que continuava a verificar-se na população portuguesa no século XIX veja-se VICENTE, Ana. As Mulheres Portuguesas vistas por viajantes estrangeiros. Lisboa: Gótica, 2001, p. 134. 
abastecimento de água, tendo, por isso, que recorrer aos fontanários. Em 1807, foi aberto um poço no quintal. No entanto, o consumo da água recolhida em poços e fontes, por não ser devidamente tratada, constituía um perigo para as populações ${ }^{44}$. Ao contrário do que sucedia com outros estabelecimentos hospitalares do distrito de Viana do Castelo, que eram considerados um risco para a saúde pública, o Hospital da Caridade estava localizado fora da malha urbana e destacava-se pela ordem e pela limpeza que imperavam nas suas instalações ${ }^{45}$.

A partir dos anos 60 do século XIX, os asilados passaram a estar todos reunidos numa só camarata. Procedeu-se, igualmente, à edificação de um refeitório e a cozinha foi melhorada. Por outro lado, procurou-se tornar o quotidiano dos asilados mais confortável, através da doação de roupa, louça, móveis e outros utensílios. Para que tal fosse alcançado, procedeu-se à angariação de recursos financeiros, recorrendo não só a donativos e legados, mas também à realização de bailes de máscaras e ao aluguer do teatro. Entre os legados, são de destacar os dos "brasileiros", que, do outro lado do Atlântico, deram o seu contributo: o Comendador João Pereira da Rocha Viana, que vivia no Rio de Janeiro e, na passagem por Viana do Castelo, entregou $200 \$ 000$ réis; Manuel José Fiúza da Costa ofertou $237 \$ 372$ réis; António Baptista Camacho e Joaquim Baptista Camacho, irmãos, através de uma subscrição pública realizada no Brasil, conseguiram 162\$255; José Joaquim de Amorim, no regresso a Viana do Castelo, proveniente do Rio de Janeiro, concedeu $80 \$ 000$ réis. Em 1869, José de Miranda Carvalho deixou uma elevada soma em dinheiro ao Hospital, o que permitiu o alargamento da sua função assistencial a um maior número de necessitados.

No dealbar da década seguinte, a Congregação decidiu avançar com a edificação de um novo espaço que permitisse albergar um total de 70 entrevados. A proposta previa a criação de um novo hospital na cerca do convento de Santo António, cedida à instituição. Para o efeito foi aberto um concurso, que só foi encerrado em 1873.

44 ACHVENSC. Livro de Actas 1, fl. 26.

45 Arquivo Histórico do Governo Civil de Viana do Castelo (doravante AHGCVC), Assistência e saúde pública, assistência social e saúde pública - Estabelecimentos de saúde, não paginado. 
Os projetos apresentados foram avaliados, depois, por um júri presidido pelo Marquês de Sá da Bandeira. Todavia, a deliberação da Congregação foi cancelada por causa do traçado do caminho-deferro.

Em 1882, morreu Mateus José Barbosa e Silva, o homem que esteve à frente dos destinos da instituição durante 33 anos, sem ter cumprido o seu desejo de edificar um novo hospital para acolher os entrevados. Em sua substituição, assumiu a liderança António Alberto da Rocha Páris.

As tentativas para obtenção de um novo espaço persistiram, agora com êxito. A 20 de agosto de 1887, o governo concedeu à Congregação o convento de Santa Ana. Contudo, esta doação só poderia ser consumada após o falecimento da última freira que ali se encontrava. O que sucedeu em 1895. Esta solução inscrevia-se na política de reaproveitamento das antigas estruturas monacais e conventuais, que, em Portugal, não constituíram uma solução estruturada, dado que vários esforços para a reutilização dos bens da Igreja, nacionalizados após a imposição da ordem liberal, não passaram de meras hipóteses que nunca saíram do papel.

Em 1894, a Congregação de Nossa Senhora da Caridade já tinha elaborados novos estatutos, que foram aprovados por alvará de 4 de novembro de 1897. Estes apresentam ligeiras alterações em relação aos primeiros. No respeitante à administração, para além das funções anteriormente previstas, previam a existência de quinze zeladores ou irmãos do mês, que ficavam responsáveis pela gestão interna do hospital. Estes zeladores, juntamente com os nove mesários, constituíam o definitório, que poderia ser convocado para consulta sobre qualquer assunto de maior gravidade e que não deveria ser tratado em assembleia geral. Nesta teriam assento todo os irmãos do sexo masculino. À medida que a organização da instituição se vai complexificando, torna-se mais explícita a função de cada um dos membros dos diferentes órgãos e as competências associadas aos cargos que hierarquizavam a instituição. No atinente aos critérios de admissão de asilados, a ênfase não era colocada na idade avançada, associada à decrepitude, mas em todos os elementos que pudessem concorrer para que o indivíduo ficasse impossibilitado não só de granjear a sua subsistência, mas também de ser esmolado. Assim, além da idade outros fatores foram considerados, designadamente a 
doença e as dificuldades de locomoção. A pobreza continuava também a ser uma condição sine qua non para ingressar no Hospital da Caridade.

Uma vez admitidos, os asilados deviam respeitar as regras da instituição e colaborar na realização de algumas tarefas do seu quotidiano, como, por exemplo, na limpeza das instalações e na feitura das camas. No entanto, como facilmente se prevê, não seria fácil a prestação destes serviços, por se tratar de pessoas muito debilitadas ou incapacitadas.

O novo regulamento previa a existência de pensionistas e, desde que a capacidade de acolhimento o permitisse, os quartos particulares deviam ser atribuídos, mediante o pagamento de uma quota diária, a doentes crónicos ou incapacitados. Admitia ainda a assistência domiciliária, à semelhança do que já sucedia com outras instituições da cidade, como a Santa Casa da Misericórdia. Deste modo, podemos considerar que os impedimentos espaciais não constituíam um obstáculo de maior à prática da assistência.

Nos tempos que se seguiram, houve diversas alterações na vida da Congregação. A igreja do convento passou para as suas mãos e, em 1905, abriu um novo espaço no terreno que pertencia ao antigo convento, para acolher os 80 asilados que havia na altura. $\mathrm{Na}$ inauguração das novas instalações, as portas do asilo abriram-se à comunidade e as forças vivas da cidade de Viana do Castelo marcaram presença, o que constituiu uma demonstração da importância da instituição na sociedade vianense.

No século XX, assiste-se à proliferação de instituições vocacionadas para os idosos. A sua criação resultou, sobretudo, de iniciativas particulares, com destaque para os "brasileiros" bemsucedidos. Movidos pelo altruísmo, mas também, em muitos casos, pela busca de prestígio social e até de protagonismo político, destinaram parte da riqueza conseguida no Brasil a obras de cariz social, tendo como principais destinatários os mais carenciados e os desprotegidos.

RECEBIDO EM: 01/03/2017

APROVADO EM: 01/06/2017 